\title{
MARCUSE: A DESCOBERTA DO PRINCÍPIO DE DESEMPENHO ENQUANTO PRINCÍPIO DE REALIDADE DA SOCIEDADE CAPITALISTA
}

Marcelo Barbosa ${ }^{1}$

\begin{abstract}
RESUMO: Com o princípio de desempenho Marcuse se propõem a fazer uma análise crítica da psicanalise de Freud, e a interage com concepção crítica, histórica e dialética do pensamento marxista. Colocando assim em evidencia uma repressão excessiva que molda nossa realidade. O lugar social do indivíduo passa a ser o resultado do controle de seu libido e de sua energia vital, e suas pulsões são direcionadas como forma de controle na manutenção de um princípio de realidade dominante. Para tanto, o princípio de desempenho falasiosmente se apresenta como o único possível, e libera o mesmo tempo que controla as pulsões dos indivíduos.
\end{abstract}

Palavras-chaves: Marcuse; Psicanalise; Libido; Sociedade capitalista.

\section{MARCUSE: THE DISCOVERY OF THE PERFORMANCE PRINCIPLE AS A PRINCIPLE OF REALITYOF CAPITALIST SOCIETY}

\begin{abstract}
With the principle of performance Marcuse they propose to make a critical analysis of the psychoanalysis of Freud, and the interaction with critical, historical and dialectical conception of the Marxist thought. Thus putting in evidence an excessive repression that shapes our reality. The social place of the individual becomes the result of controlling his libido and vital energy, and his drives are directed as a form of control in maintaining a principle of dominant reality. For this purpose, the performance principle falsely presents itself as the only possible one, and frees up the same time that it controls the drives of individuals.
\end{abstract}

Keyword: Marcuse; Psychoanalysis; Libido; Capitalist Soiety

Este artigo se propõe a expor de que modo Marcuse insere a psicanalise freudiana na teoria crítica e interage com conceitos do pensamento marxista. Ao se apropriar dos conceitos de Freud, Marcuse atribui uma concepção crítica, histórica e dialética, pretendendo revelar as novas formas de expropriação do trabalho que o sistema capitalista desempenha, ampliando sua dominação e exploração. Assim, Marcuse encontra na psicanalise um meio para revelar as novas formas de dominação capitalista

\footnotetext{
1 Mestre em Filosofia pela Universidade Estadual do Oeste do Paraná - UNIOESTE. E-mail: barbosa_mondai@hotmail.com
} 
Se, por um lado, é principalmente pelo viés dos valores culturais que Marcuse desenvolve o potencial crítico da psicanálise, por outro lado, parte do pressuposto de que, as relações sociais entre os indivíduos são determinadas pelas relações de produção de mercadorias e pela divisão de classes da qual a sociedade é composta. Sendo assim, os valores culturais derivados da socialização e da relação social entre os indivíduos, podem ser substituídos ou mesmo serem restringidos a valores culturais que interessam somente a um princípio de realidade dominante.

Marcuse torna política as categorias da psicologia, percebendo que os processos psíquicos dos indivíduos são absorvidos pela função deste no Estado, nos processos de produção e de consumo. De modo que, os valores culturais que determinam as relações entre os indivíduos, funcionem como instrumentos de controle repressivo, tencionando a felicidade e a libido dos indivíduos em favor do aparato tecnológico dominante. Acontece desse modo que, a perturbação particular do indivíduo, que tem seus processos psíquicos absorvidos em vista de uma realidade dominante, se reflete numa perturbação do todo social, implicando numa desordem geral, onde nem um é particular e nem o todo é social, ocorrendo uma alienação dos valores culturais.

Marcuse busca desenvolver uma análise crítica dos acontecimentos políticos e sociais a partir das noções da psicologia. O lugar social ${ }^{2}$, ou seja, o meio de onde fala o indivíduo, fornece o fundamento histórico para pensar a interação com a teoria crítica marxista. O lugar social é o processo social concreto que mostra a relativização da pretensão universalista da psicanálise, é por ele que os valores sociais são medidos, é onde o indivíduo desenvolve sua personalidade, aceitando ou se contrapondo ao status quo e também é o que determina o que é ou não aberrante para a sociedade.

O potencial concreto do lugar social está nos "valores do meio que decidem se certos comportamentos são ou não aberrantes, e tais valores variam de geração para geração e de classe

\footnotetext{
2 - Usado por Siegfried Bernfeld (1892-1953) como crítica marxista a pretensão universalista do freudismo, mostrando sua vinculação aos processos sociais concretos. O lugar social é, desse modo, os valores que determinam se um comportamento é ou não aberrante em um meio específico. Bernfeld aponta ainda que a maior parte da população se encontra na situação de Tântalos, ou seja, está destinada a não poder satisfazer adequadamente as suas necessidades.
} 
social para classe social” (ROUANET, 2001, p. 20). Para Rouanet, a maioria da população vive em "situação de Tântalo", ou seja, suas necessidades nunca são satisfeitas adequadamente, e estas estão sempre vinculadas a privação da necessidade de outros. O que se questiona é: como uma classe social composta pela maioria oprimida, aceita a opressão pela minoria? Aí se encontra para Marcuse o papel crítico da psicanálise, nos possibilita compreender o papel da influência ideológica burguesa/capitalista, e na fixação de elementos que levam a classe operária a respeitar cegamente a autoridade imposta e a amar aquilo que o oprime.

Para tanto, o recalque e a sublimação são elementos importantes na incorporação da ideologia dominante. Funcionam como uma gratificação compensatória das pulsões não realizadas, "o círculo se completa: a cultura, em sua dimensão moral, é utilizada para impedir a gratificação pulsional. Parte do afeto 'censurado' é recalcado, e parte é sublimado" (ROUANET, 2001, p. 24), ou seja, o recalque funciona como a introjeção dos valores mesmo que o indivíduo não se identifica. O pensamento de Freud, principalmente nas obras Totem e Tabu (1913), O Mal-estar na civilização (1930) e Moisés e o Monoteísmo (1939), são usados como instrumento crítico, o que permite a Marcuse lançar perspectiva de uma ordem além da dominação. Mas como?

A Utopia de Marcuse se funda na tensão entre Eros e Thanatos ${ }^{4}$. É pela teoria das pulsões de Freud - O Mal-estar na Civilização -, que Marcuse visualiza a nova forma de dominação e a possibilidade subversiva de um novo Princípio de Realidade. A vida para Freud é orientada pelas pulsões de Eros e Thanatos, que representam as pulsões de vida e de morte respectivamente. O Princípio de Prazer (Eros) representa a natureza sexual, contendo a libido, responsável pelo movimento de prolongar a vida, e o princípio de morte (Thanatos), é movido pela agressividade e destruição da vida. A vida,

\footnotetext{
3 - O nome Tântalo aparece no Canto XI da Odisséia de Homero, nos versos 582-592. Tântalo certa vez, ousando testar a omnisciência dos deuses, roubou os manjares divinos e serviu-lhes a carne do próprio filho Pélope num festim. Como castigo foi lançado ao Tártaro, onde, num vale abundante em vegetação e água, foi sentenciado a não poder saciar sua fome e sede, visto que, ao aproximar-se da água esta escoava e ao erguer-se para colher os frutos das árvores, os ramos moviam-se para longe de seu alcance sob a força do vento. A expressão Suplício de Tântalo refere-se ao sofrimento daquele que deseja algo aparentemente próximo, porém, inalcançável, a exemplo do ditado popular "Tão perto e, ainda assim, tão longe".

4 - Eros é uma palavra que deriva do Latim que significa amor, na mitologia grega seu significado expressa o amor, o desejo e atração sexual. Desse modo, a pulsão libidinal de Eros une as pessoas pelo anseio da civilização. Thanatos é uma palavra que derivada do grego, que significa morte. Freud utiliza para explicar a pulsão de morte no indivíduo. Se refere a morte social, aquela pulsão que leva o indivíduo a loucura e ao suicídio.
} 
para Freud, consiste na interação e no conflito destas duas classes de instintos. Mas, é no Princípio de Prazer (Eros) que o processo civilizatório está apoiado, por ser de natureza sexual tem a capacidade de juntar as pessoas e assim prolongar a vida. Mas, a vida em civilização requer a sublimação de alguns prazeres, ou de pulsões. A sublimação das pulsões, são basicamente uma reorientação da libido para finalidades primárias e não sexuais, ou seja, no processo civilizatório nós não realizamos o Eros diretamente, nossas pulsões e nossos afetos são suprimidos e gratificados, e a gratificação é canalizada para a produção de "cultura".

Para Freud, o processo civilizatório está necessária e diretamente ligado a um caráter repressivo, e de renúncia aos instintos. Para ele, possuímos uma herança arcaica de experiências históricas que estão presentes em nosso inconsciente. O parricídio ${ }^{5}$ dos irmãos e o estabelecimento de totens e tabus são para FREUD (v. 23, p. 53), o início da civilização e do processo religioso. Para o psicanalista, os primórdios da moralidade e da justiça se encontram na renúncia aos instintos; no reconhecimento das obrigações mútuas; na introdução das instituições; e no reconhecimento destas como invioláveis e sagradas. Isto tudo possibilita a geração da primeira forma de organização social.

Após o assassinato do pai, pelo clã dos irmãos, surge o sentimento de culpa. O pai que antes negava a gratificação pulsional dos filhos, após ser assassinado, surge como totem, "os parricidas rebeldes agem unicamente para frustrar a primeira consequência, a ameaça: restabelecem a dominação substituindo um pai por muitos e, depois, deificando e internalizando o pai único" (MARCUSE, 1975, p. 74). Marcuse percebe que o indivíduo dissolvido na ordem social dominante, enfrenta a repressão geral da humanidade, e afirma que, "a autoconsciência e a razão fez do homem à imagem e a semelhança da repressão, interna e externa" (MARCUSE, 1975, p. 67). Segundo Marcuse, o sentimento de culpa gerado pela morte do pai, é uma das causas da derrota dos movimentos revolucionários.

A causa está no momento em que "a dominação despersonifica-se, o poder dominador do pai é, substituído pela administração, e os indivíduos inseridos nos sistema do trabalho passam a reproduzir sua própria repressão" (VALE, 2004, p. 26).

\footnotetext{
5 - Em 1913, no texto "Totem e Tabu", Freud inventa um mito de origem para toda a humanidade e propõe o parricídio como o crime primevo fundador da cultura, vinculado a obra crime e castigo de Fiódor Dostoiévski.
} 
Desse modo, a rebelião que era para ser libertadora toma o rumo da sociedade do clã dos irmãos, personificando o pai nas instituições que garantem a vida social e a reprodução de sua lógica, "A revolta contra o pai primordial eliminou uma pessoa individual que podia ser (e foi) substituída por outras pessoas; mas quando o domínio do pai se expandiu, tornando-se o domínio da sociedade, tal substituição não parece ser possível, e a culpa torna-se fatal” (MARCUSE, 1975, p. 93).

Freud atribui ao sentimento de culpa o papel decisivo no desenvolvimento da civilização, e ainda correlaciona o progresso ao sentimento de culpa. Desse modo, o sentimento de culpa é a racionalização que inibe o prazer e a agressividade, sustentando o progresso da civilização, daí o permanente mal-estar na civilização. Assim, seguindo a argumentação de Freud, se percebe que é pelo meio da repressão que se possibilita o processo civilizatório. O prazer imediato e instintivo é adiado em busca de um futuro civilizatório, de modo que podemos agora compreender a afirmação de Marcuse: "se a ausência de repressão é o arquétipo de liberdade, então a civilização é a luta contra essa liberdade" (Marcuse, 1975, p. 35). A civilização se mostra contra a efetivação da liberdade.

O que Marcuse observa, é que Freud não contextualiza os sacrifícios dos sentidos pela busca da civilização, e que também Freud não faz uma distinção entre repressão instintiva e civilizatória em relação a repressão instrumentalizada. A psicanálise entende a repressão socialmente aceita como um fenômeno natural entre a contraposição do princípio de prazer e o princípio de realidade, sendo que o último é regido pela repressão da excitação mental do primeiro, os sacrifícios aparecem como necessários em vista da civilização.

O Princípio de Prazer (Eros) é dessexualizado pelo processo de sublimação, o que possibilita o processo de civilização. Consequentemente, não realiza suas pulsões, o Eros é enfraquecido. "E a dessexualização, ao enfraquecer o Eros, liberta os impulsos destrutivos, originada na renúncia e desenvolvendo-se sob uma progressiva renúncia, a civilização tende para a autodestruição" (MARCUSE, 1975, p. 87). Temos assim um princípio de realidade civilizatório que é o resultado de uma repressão constante que organiza os indivíduos a partir da renúncia de seus instintos. O que objetivamos explicitar aqui, seguindo a indicação de Marcuse, é a existência do princípio de desempenho, que é um princípio de realidade modelado por uma mais-repressão, essa, 
excede o processo civilizatório e serve a uma lógica de dominação dos interesses de grupos capitalistas que, desse modo, organizam a estrutura instintiva dos indivíduos e instrumentalizam o interesse da sociedade.

Marcuse ressalva que a partir de Freud, se torna possível reconhecer que até hoje a civilização se estruturou como dominação. Mas, a ausência da perspectiva do processo histórico no pensamento de Freud, evidencia um dos limites desta teoria, fazendo com que Marcuse introduza os conceitos de mais-repressão e princípio de desempenho, de modo a evidenciar os potenciais críticos ocultos na Teoria Tradicional de Freud. Schütz (2013) observa que a falta do caráter histórico na teoria de Freud não permite a distinção entre uma repressão instintiva necessária e uma repressão instrumentalizada.

Se compreendermos como suposto o sacrifício em vista da civilização, "uma realidade repressiva específica poderia aparecer enquanto representante do próprio princípio de realidade enquanto tal, não percebendo a repressão excessiva (maisrepressão) que eventualmente poderia existir a serviço de interesses de dominação" (SCHÜTZ, 2013, p. 5). Ou seja, existe certa racionalidade na dominação, que, excedendo a repressão instintiva necessária, impõem a mais-repressão. O princípio de desempenho é desse modo, a representação do princípio de realidade moldado pela mais-repressão, que mantém o privilégio e o poder de determinados grupos e classes sociais.

O princípio de desempenho se destaca também por uma gratificação imediata da a libido, absorvendo o princípio de prazer, e lhe conferindo um véu de liberdade enquanto o reprime. E dessublimação repressiva é a substituição de uma gratificação mediada por uma gratificação imediata e, acontece pela absorção do princípio de razer, que passa a estar a serviço da manutenção do princípio de desempenho. Ou seja, a dessublimaçao repressiva ocorre basicamente pela liberalização da sexualidade, que, assim como ocorre com a liberalização da cultura, é liberada afim de intensificar a dominação.

A dessublimação repressiva contrai a libido, e reduz o erótico à experiências e satisfações sexuais/genitais. Sabe-se que a libido transcende as zonas erógenas, mas, no interior da lógica repressiva do princípio de desempenho: "O efeito é uma localização e contração da libido, a redução do erótico à experiência e satisfação sexual” (MARCUSE 2015, p. 98). A catexia libidinal, que na psicanalise designa a energia psíquica investida 
em um objeto, podendo ser pessoa, coisa ou causa é a demonstração de que a libido transcende as zonas erógenas, o que é bloqueado no sistema de dominação. Ou seja, a libido passa a ser gerenciada somente como sexo, e não mais como prazer polimórfico com as coisas.

A sexualidade passa a ser liberada sob formas socialmente útil, a atuação direta na esfera sexual "opera como o subproduto dos controles sociais da realidade tecnológica, que amplia a liberdade enquanto intensifica a dominação" (MARCUSE, 2015, p. 98). A atuação da dessublimação repressiva é responsável pelo enfraquecimento das tendências sociais que negam o princípio de desempenho. Enquanto ferramenta ideológica, ela amplia a aparência de liberdade, enquanto intensifica a dominação, é uma pré-condição para aceitar espontaneamente o princípio de desempenho a partir de uma libertação controlada, que ajusta o prazer, reduz o sentimento de culpa e desse modo, enfraquece a revoltados instintos contra a realidade opressora.

Falaciosa ou enganosamente, mesmo sendo um princípio de realidade histórico específico, o

princípio de desempenho é apresentado como único princípio possível e até mesmo necessário para o desenvolvimento da civilização. E é justamente esta falácia ideológica que passa então a ser desconstruída por Marcuse. Esta apropriação crítica de umas das questões centrais do pensamento de Freud possibilitou a Marcuse a identificar nas próprias manifestações do princípio de realidade específico da sociedade moderna, antes um bloqueio do que uma necessidade para o desenvolvimento da civilização.

Deste modo, para Marcuse, tornou-se possível visualizar uma nova análise da práxis social, orientada pelo horizonte crítico constituído a partir de Freud. O princípio de desempenho está "materializado num sistema de Instituições" (MARCUSE, 1975, p. 36), que, com todo seu aparato tecnológico e científico é capaz de amenizar a luta do indivíduo pela existência, porém, o sistema controla os seus súditos pelos bens de consumo supérfluos e na reorientação da energia sexual para o trabalho alienado.

\section{REFERÊNCIAS BIBLIOGRÁFICAS}

FREUD, Sigmund. Obras psicológicas completas de Sigmund Freud. V. 18. Além do princípio de Prazer. Rio de Janeiro, RJ: Imago, 1996. 
Obras psicológicas completas de Sigmund Freud. V. 21. Futuro de uma ilusão e mal estar na civilização. Rio de Janeiro, RJ: Imago,1996.

MARCUSE, Herbert. A dimensão estética. Trad. Maria Elizabete Costa. Lisboa: Edições 70, 2007.

A grande recusa hoje. Trad. Isabel Loureiro e Robespierre de Oliveira. Petrópolis, RJ: Vozes, 1999.

Cultura e psicanálise. Trad. Wolfgang Leo Maar, Isabel Loureiro e Robespierre de Oliveira. São Paulo: Paz e Terra, 2001.

. Cultura e sociedade. Vol. I. Trad. Wolfgang Leo Maar, Isabel Loureiro e Robespierre de Oliveira. RJ: Paz e Terra, 1998.

Cultura e sociedade. Vol. II. Trad. Wolfgang Leo Maar, Isabel Loureiro e Robespierre de Oliveira. RJ: Paz e Terra, 1998.

Eros e civilização: uma interpretação filosófica do pensamento de Freud. Trad. Álvaro Cabral. 6 Ed. Zahar Editores. Rio de Janeiro, 1975.

Razão e Revolução: Hegel e o Advento da teoria social. Trad. Marília Barroso. São Paulo: Paz e Terra, 2004.

Tecnologia, guerra e fascismo. Trad. Maria Cristina Vidal Borba. São Paulo: Fundação Editora da UNESP, 1999.

MARX, Karl. Manuscritos econômicos-filosóficos. Trad. Jesus Ranieri. São Paulo, SP: Ed. Boitempo, 2008.

NOBRE, Marcos. Curso livre de teoria crítica. Caminas - SP: Papirus, 2008.

SCHÜTZ, Rosalvo. O deslocamento do lugar social da negação em Herbert Marcuse. Argumentos. Ano 4, p. 188-198, 2012. Disponível em: http://www.filosofia.ufc.br/argumentos/pdfs/educacao_8/17_\%20parte_2_deslocamento _do_lugar_social.pdf

Por um outro princípio de realidade: novos lugares e motivos sociais de negação segundo Herbert Marcuse. Educação e filosofia. Uberlândia, V. 27, n. 54, p. 699-718, jul/dez. 2013. ISSN 0102-6801. Disponível em: http://www.seer.ufu.br/index.php/educacaofilosofia/article/view/17344/12709.

- Trabalho alienado e propriedade privada: desvendando imbricações ocultas. Revista eletrônica Espaço acadêmica. V.87, p. 87, 2008. 